\title{
Bases Cartográficas para Municípios de Pequeno Porte geradas por Informação Geográfica Voluntária
}

\author{
Cartographic Bases for Small Cities generated by Voluntary Geographic \\ Information
}
Priscila L. Silva1; Vinicius G. Sperandio'; Larissa F. Rodrigues ${ }^{2}$; Vitor E. C. Dias $^{2}$; Layane B. S. Loti ${ }^{1}$; Matheus H. M. Lisboa ${ }^{1}$; Gabriel D. Oliveira ${ }^{1}$; Gisele H. B. Miranda ${ }^{1}$; Gustavo S. Martins ${ }^{2}$; Cleiton R. Monteiro ${ }^{2}$; Vinicio F. Mendes ${ }^{2}$ e Jugurta Lisboa-Filho ${ }^{2}$

Recebido em abril de 2018. Aprovado em novembro de 2018.

\begin{abstract}
RESUMO
A informação geográfica é utilizada constantemente no processo de tomada de decisão relacionado a problemas geoespaciais. Com a disseminação da tecnologia de informação na sociedade, a geração de dados espaciais por meio do mapeamento baseado em Informação Geográfica Voluntária (VGI) supera os procedimentos convencionais de mapeamento em termos de custo, qualidade temática e simplicidade. Este artigo é o primeiro a considerar o uso de VGI e programas gratuitos para elaborar bases cartográficas com alta acurácia temática e temporal, sendo um bom primeiro passo para o desenvolvimento de pesquisas nesta área. Os resultados experimentais mostram o potencial da VGI como uma ferramenta para auxiliar gestores municipais no processo de decisão baseado em análises espaciais, permitindo uma melhor utilização dos recursos públicos, aumento da qualidade dos serviços oferecidos aos cidadãos e redução dos custos operacionais da administração pública.
\end{abstract}

PALAVRAS-CHAVE: VGI. OpenStreetMap. Banco de dados geográficos.

\begin{abstract}
The Geographic information is constantly used for decision-making in various geospatial problems. With the increasing spread of technology in society, the generation of spatial data through of maps based in VGI outperforms the conventional mapping procedures in terms of cost, quality and simplicity. Our work is the first to consider the use of VGI and free
\end{abstract}

\footnotetext{
${ }^{1}$ Programa de Pós-graduação em Engenharia Civil, Universidade Federal de Viçosa, Brasil. E-mail: \{priscila.l.silva; layane.loti; matheus.lisboa\}@ufv.br

${ }^{2}$ Programa de Pós-graduação em Ciência da Computação, Universidade Federal de Viçosa, Brasil.

E-mail: \{vinicius.sperandio; larissa.f.rodrigues; vitor.dias; jugurta\}@ufv.br
} 
software to elaborate cartographic bases with high thematic accuracy and temporal, being a good first step for the development of the researches in this area. The experimental results show the potential of the VGI such as a tool to support municipal managers in the decision process based on spatial analysis, allowing a better use of public resources, increasing the quality of services offered to citizens and reducing the operational costs of public administration.

KEYWORDS: VGI. OpenStreetMap. Geographic Database.

\section{Introdução}

A Internet e os dispositivos móveis como os smartphones popularizaram e disseminaram o uso de informações geográficas. Atualmente este tipo de informação está disponível gratuitamente para um número incontável de usuários. Por exemplo, por meio do uso de mapas dinâmicos, chamados WebMaps, os usuários podem visualizar e interagir com as informações apresentadas na forma de mapas. Atualmente, a interação com algumas plataformas permite que os usuários sejam mais do que apenas consumidores de dados e atuem também como sensores ou produtores de informação geográfica, de forma voluntária (GOODCHILD, 2007). Informação Geográfica Voluntária (VGI) é a principal fonte de dados em plataformas como Wikimapia e OpenStreetMap (OSM). Nestas plataformas, os usuários podem acrescentar aos mapas dados sobre uma área ou região de seu conhecimento (BUDHATHOKI, 2007).

O projeto OSM foi lançado em 2004 com o propósito de criar um mapa editável do mundo inteiro, onde as informações existentes são de livre acesso e utilização, iniciou-se com o mapeamento de ruas e estradas e evoluiu permitindo a representação de diferentes objetos geográficos (ARSANJANI et al., 2015).

A base de dados do OSM é mantida por uma comunidade constituída de colaboradores que mapeiam voluntariamente estradas, ruas, edificações públicas, estabelecimentos comerciais nas cidades e campos espalhados por 
todo o planeta. A plataforma OSM conta com um GeoPortal (www.openstreetmap.org) que apresenta diferentes feições mapeadas a partir de imagens de satélites e fornece ferramentas que permitem a edição e inserção de novas feições. As alterações feitas podem ser salvas, e, após, são analisadas por grupos de profissionais capacitados, que agem como moderadores. Finalmente, as alterações se tornam efetivas e podem ser visualizadas e exportadas (em formato .osm) por qualquer usuário (HAKLAY e WEBER, 2008).

As informações disponibilizadas possuem livre acesso de utilização, sujeita à Open Database License, podendo ser exportadas e inseridas em Sistemas de Informações Geográficas (SIG) e em Sistemas Gerenciadores de Bancos de Dados (SGBD) geográficos (ex.: PostGIS) e podem ser manipuladas através destes (ODbL, 2017).

O uso de informação geográfica voluntária em diversos contextos tem sido amplamente investigado na literatura. Wan et al. (2014), propuseram a construção de um banco de dados georreferenciado de desastres hidrológicos ocorridos em todo o planeta a partir da colaboração de usuários e de informações oficiais. Entre as aplicações baseadas em compartilhamento de informação em mídias sociais, o trabalho proposto por Kusumo et al. (2017) apresenta um estudo de caso feito em Jacarta na Indonésia, mostrando como VGI e compartilhamento de informações no Twitter podem auxiliar no planejamento de abrigos de evacuação e ser crucial para situações de emergência.

No Brasil, destaca-se o uso de VGI para gestão de riscos hidrológicos. Horita et al. (2015) e Moreira et al. (2015) apresentaram iniciativas para monitoramento de risco de enchentes. Hirata et al. (2015) descrevem o uso de VGI para identificar pontos de alagamento na cidade de São Paulo. Martins et al. (2017) utilizaram VGI para que cidadãos realizem registros acerca da situação das estruturas relacionadas à microdrenagem urbana na cidade de Florianópolis. 
Câmara et al. (2017) descrevem a plataforma ClickOnMap, que foi desenvolvida para configuração de aplicações de coleta de VGI que podem ser customizadas rapidamente, possibilitando atender situações de emergências. A plataforma inclui um aplicativo para dispositivos móveis e permite a geração de colaborações em tempo real. Exemplos de aplicações VGI desenvolvidas nesta plataforma são: Cidadão Viçosa, Mossoró Crimes e Gota D’Água. Estes sistemas mostram o potencial em utilizar VGI em questões de segurança pública, saúde, entretenimento e infraestrutura.

Recentemente, Heider et al. (2018) investigou em seu trabalho como o uso de VGI pode ser fundamental no fornecimento de informações espaciais para melhorar a realidade nos assentamentos informais e realizaram um estudo para detectar a periurbanização na zona de conservação da Cidade do México, integrando as principais estradas e os padrões dos assentamentos informais por meio da rede viária do OSM.

A dificuldade de recursos financeiros e a escassez de mão-de-obra qualificada para produção, disponibilização e manutenção de informação geográfica, na grande maioria dos municípios brasileiros, principalmente os de pequeno porte, transforma a VGI em uma boa alternativa para geração de uma base cartográfica para estes munícipios. A gestão de desastres naturais, preocupações com as questões de infraestrutura urbana, saúde e segurança pública são exemplos do uso bem-sucedido de VGI. Este trabalho se diferencia dos que foram anteriormente citados por propor a construção de uma base cartográfica capaz de auxiliar gestores municipais em atividades de tomada de decisão. Acredita-se que essa proposta pode ser eficaz e proporcionar melhorias nas tarefas de gestão da administração pública.

Desta forma, o principal objetivo deste trabalho é descrever como uma base cartográfica gerada por mapeamento colaborativo, através da plataforma OSM, pode possibilitar aos gestores de municípios de pequeno porte tomarem decisões quanto a administração territorial, utilizando apenas sistemas de software livre. 


\section{Material e Método}

No desenvolvimento deste estudo foram empregados apenas sistemas de software livre, incluindo a plataforma OSM. O uso dessas ferramentas permitiu, sem nenhum custo e estimulando o uso de conhecimentos locais, a elaboração de bases cartográficas municipais confiáveis em relação à descrição e atualização dos dados.

O presente trabalho foi desenvolvido de acordo com o método mostrado na Figura 1 e consiste nas seguintes etapas: 1) definição dos municípios; 2) criação, edição e enriquecimento dos dados/feições dos municípios; 3) engenharia reversa; e 4) manipulação dos dados gerados.

Figura 1 - Método proposto

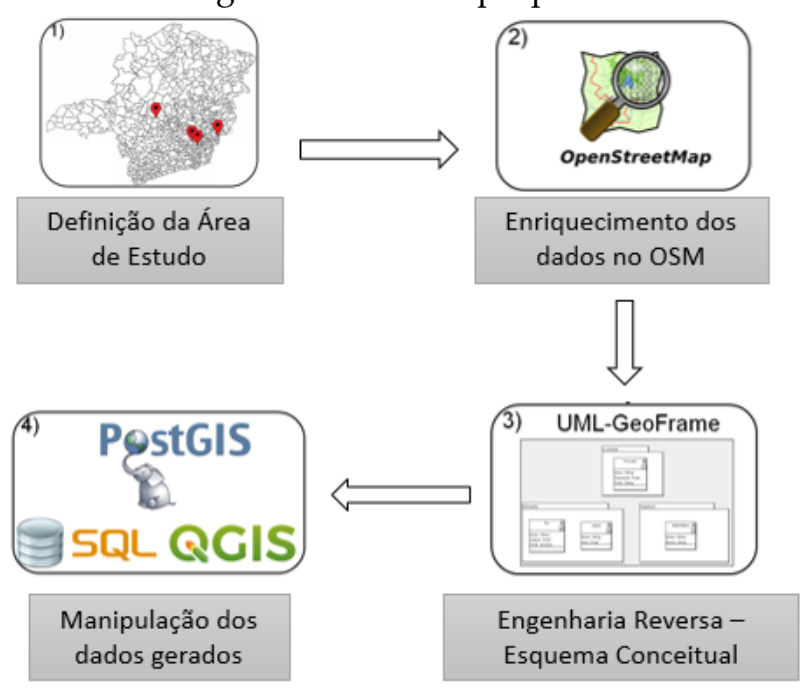

Fonte: elaborada pelos autores.

A primeira etapa consistiu na escolha de quatro municípios para criação e edição de dados espaciais no OSM. Foram escolhidos, por questão de origem e conhecimento dos autores, os municípios de Florestal, Manhumirim, Paula Cândido e Piranga, todos de pequeno porte localizados no estado de Minas Gerais, sendo estes mostrados na Figura 2. O município de Florestal se localiza na mesorregião metropolitana de Belo Horizonte, possui área aproximada de $194,242 \mathrm{Km}^{2}$ e população aproximada de 7.343 habitantes. Os 
municípios de Manhumirim, Paula Cândido e Piranga, se localizam na Zona da Mata Mineira. A população de Manhumirim é de aproximadamente 22.784 habitantes e sua área é de aproximadamente 182,900 km². Já Paula Cândido possui área aproximada de $268,321 \mathrm{~km}^{2}$ e população aproximada de 9.698 habitantes. Piranga possui aproximadamente 17.918 habitantes e área aproximada de $658,812 \mathrm{~km}^{2}$ (IBGE, 2017). Na base do OSM, nestes quatro municípios, praticamente só existiam informações muito básicas cadastradas, como o arruamento parcial e, na maioria dos casos, sem o nome das ruas.

Figura 2 - Área de Estudo

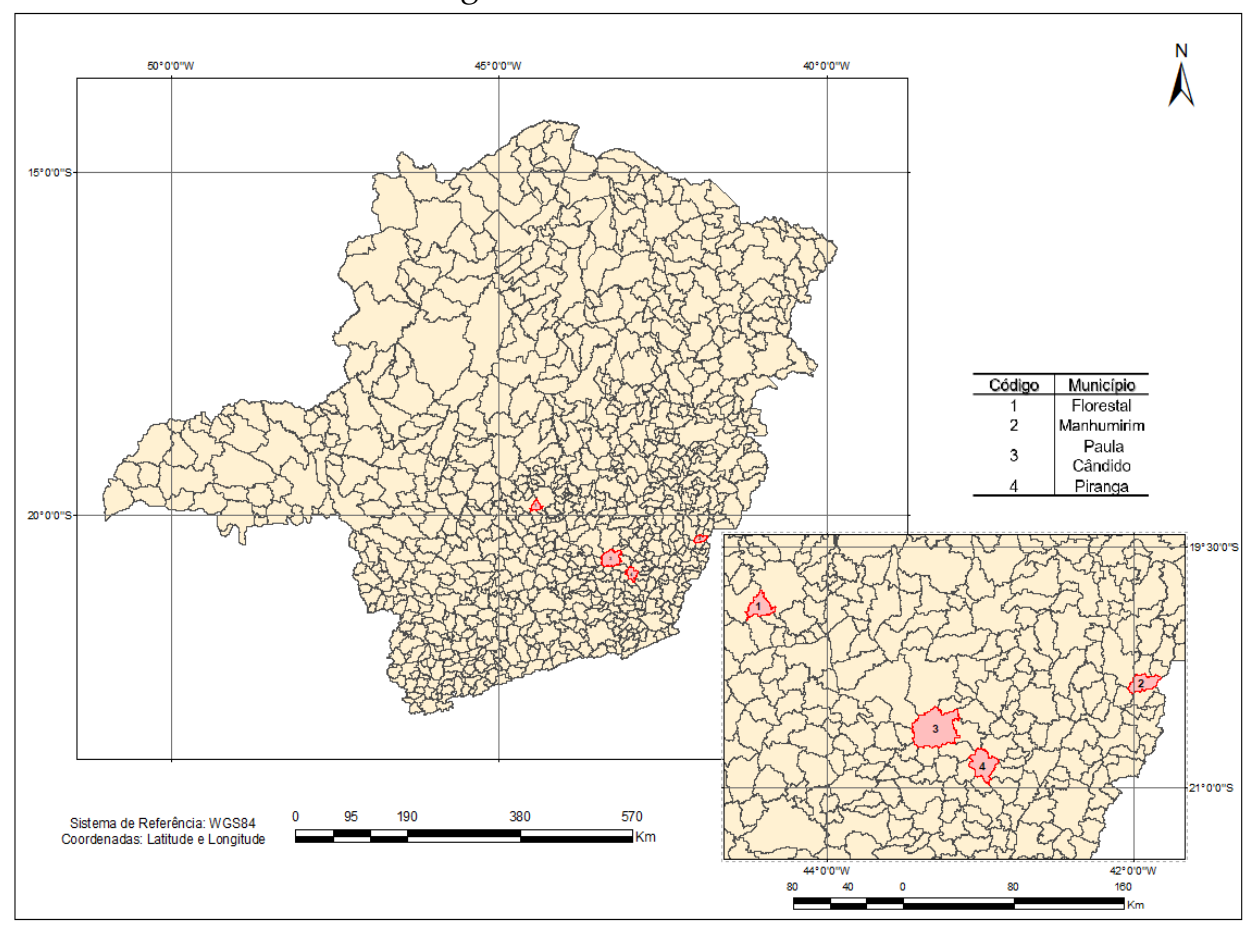

Fonte: elaborada pelos autores.

A segunda etapa consistiu na criação e edição de dados já existentes nos municípios, esta deu-se por meio da criação das feições urbanas como arruamentos e edificações, utilizando as primitivas geométricas pontos, linhas e polígonos no Geoportal OSM. O Geoportal OSM, em acordo com a Microsoft, disponibiliza em seu sistema um mosaico de imagens de satélite do Bing para que os dados sejam vetorizados sobre a mesma (OSM Wiki, 2018). 
O mosaico é formado por imagens orbitais de média resolução (LandSat e Spot) e algumas ortofotos. Sztutman (2014) avaliaram a qualidade posicional de bases de dados na Web, dentre eles Bing Maps, para o município de São Paulo/SP e encontraram uma escala de trabalho de 1/10.881. Um trabalho similar a este foi feito por Zanetti (2016), onde avaliou-se a acurácia posicional de webmaps na região de Viçosa/MG, encontrando uma escala de trabalho próxima a anterior de 1/10.000.

De acordo com Idoeta (2005), cartas na escala 1/10.000, situa-se dentro do campo das cartas cadastrais, sendo esta muitíssimo utilizada na área urbana para fins de planos diretores municipais. Estes geralmente apresentam sistemas viários completos, áreas edificadas e não edificadas, hidrografia, linhas de transmissão entre outros.

Após a criação das feições, foram fornecidos valores para seus respectivos atributos. Nesta etapa foi imprescindível o conhecimento prévio da região, por parte dos voluntários, para garantir qualidade nos dados cadastrados. Este trabalho teve como foco o cadastro das áreas urbanas municipais, arruamento, edificações, equipamentos públicos e privados, hidrografia e outros. Após a validação e aprovação dos dados, feita por responsáveis do sistema OSM, os dados foram exportados para o software QGIS, visando identificar inconsistências na geometria, conectividade e adjacência entre as linhas e os polígonos criados. Ressalta-se que nesta etapa os autores receberam elogios dos moderadores do OSM.

A terceira etapa consistiu na realização de engenharia reversa, utilizando o modelo UML-GeoFrame (LISBOA-FILHO e IOCHPE, 2008) e a ferramenta CASE ArgoCaseGeo (LISBOA-FILHO et al., 2004), para elaborar o esquema conceitual dos dados cadastrados, visando produzir os diagramas conceituais de cada município. Nesta etapa foram definidas as entidades que seriam armazenadas no banco de dados geográfico e seus relacionamentos.

O modelo UML-GeoFrame é um framework conceitual que utiliza a linguagem de modelagem unificada UML com adição de estereótipos a fim de auxiliar o projetista nos primeiros passos na geração de uma nova aplicação 
SIG (LISBOA-FILHO e IOCHPE, 2008). O modelo UML-GeoFrame suporta a maioria dos requisitos de modelagem de aplicações SIG, como múltiplas representações, aspectos temáticos, aspectos espaciais, diferenciação entre objetos convencionais e objeto/campo geográfico. A Figura 3 ilustra os elementos que podem ser utilizados na modelagem e seus respectivos estereótipos (LISBOA FILHO et al., 2004).

Figura 3 - Estereótipos do Modelo UML - GeoFrame

\begin{tabular}{|c|c|c|}
\hline $\begin{array}{l}\text { Fenômeno geográfico e } \\
\text { Objeto convencional }\end{array}$ & $\begin{array}{l}\text { Componente espacial } \\
\text { de objetos geográficos }\end{array}$ & $\begin{array}{l}\text { Componente espacial } \\
\text { de campos geográficos }\end{array}$ \\
\hline$\triangle$ Objeto geográfico & - Ponto & $\because$ Pontos irregulares \\
\hline A Campo geográfico & Linha & Grade de pontos \\
\hline & (9) Poligono & Poligonos adjacentes \\
\hline$\triangle$ Objeto nâo geográfico & * Obj. espacial complexo & Isolinhas \\
\hline \multicolumn{2}{|c|}{ «বfunçăo»> funçăo categórica } & $\begin{array}{l}\text { Grade de células } \\
\text { TIN }\end{array}$ \\
\hline
\end{tabular}

Fonte: elaborada pelos autores.

O primeiro conjunto de estereótipo "Fenômeno geográfico e Objeto convencional", é utilizado para representar os dois objetos específicos em um banco de dados geográfico, diferenciando-os entre objeto/campo geográfico e tipo de dado convencional.

Os conjuntos seguintes, "Componente espacial de objetos geográficos" e "Componentes espacial de campos geográficos", são usados para modelar fenômenos na visão de objeto e de campo, respectivamente, sendo possível a combinação de mais de um estereótipo em uma mesma classe, fazendo com que essa classe tenha múltiplas representações geográficas.

O último estereótipo <<função>> é usado para descrever o relacionamento entre fenômenos na visão de campo e objetos convencionais categóricos.

Por se tratar de uma modelagem conceitual, o seu nível de abstração é alto, portanto, critérios tecnológicos como aspectos de implementação, tipo de dados e outros não são levados em consideração, sendo assim, os esquemas de 
dados conceituais são mais fáceis de serem compreendidos por usuários finais (ELMASRI e NAVATHE, 2005). É importante que a modelagem dos dados seja acurada, pois é nela que os elementos do mundo real serão transformados e representados como elementos de um banco de dados, logo, será feita a identificação dos elementos do mundo real que tenham relação com o escopo do projeto. Uma boa modelagem reduz o número de manutenções corretivas, auxilia na compreensão das entidades e seus relacionamentos, em vista disso é possível reduzir ou até mesmo prevenir gastos futuros.

Como etapa subsequente, importou-se os dados para o SGBD PostgreSQL, com as extensões espaciais PostGIS e pgRouting instaladas. Essas extensões permitem armazenar dados espaciais em um banco de dados e efetuar consultas espaciais, topológicas e traçado de rotas sobre eles.

$\mathrm{Na}$ importação dos dados referente a malha viária a ferramenta 'osm2pgrouting', presente na extensão pgRouting, foi usada para compatibilizar a estrutura dos dados geográficos do OSM com as funções de cálculo de rota presentes no pgRouting. Detalhes sobre a conversão dos dados são detalhados por Obe e Hsu (2017).

Por fim, na quarta e última etapa foi discutida a importância da utilização dos dados coletados para muitos propósitos, e a principal abordagem foi a utilização dos mesmos na administração pública. Elaborouse consultas a fim de exemplificar o potencial de análises espaciais visando contribuir no processo de tomada de decisão na administração municipal. Alguns exemplos de consultas realizadas foram: análise de melhores locais para inserção de novos edifícios públicos; avaliação de melhores rotas; cálculo de distâncias; e comprimentos de vias. Foram avaliadas também questões ambientais como definição de Áreas de Preservação Permanente (APP) e análise de interseção, para avaliar quais vias e edificações estavam sobrepondo as APPs. 


\section{Resultados e Discussão}

Como definido na $2^{\mathrm{a}}$ etapa deste trabalho, foram realizadas contribuições na plataforma OSM de acordo com as cidades escolhidas. Foi proposta a criação e correção dos possíveis erros encontrados, melhorando assim as bases de dados a serem trabalhadas nas etapas seguintes.

No município de Florestal, por exemplo, foram realizadas 243 mudanças, entre inserções de novas informações e correções das existentes. Já no município Manhumirim foram cadastradas 83 novas edificações, além das correções elaboradas. Como exemplo dessas contribuições, a Figura 4 ilustra a evolução dos dados contidos na base do OSM para o município de Piranga e mostra a situação antes e depois das contribuições feitas pelos membros do projeto.

Figura 4 - Exemplo da evolução dos dados antes e depois das contribuições no município de Piranga

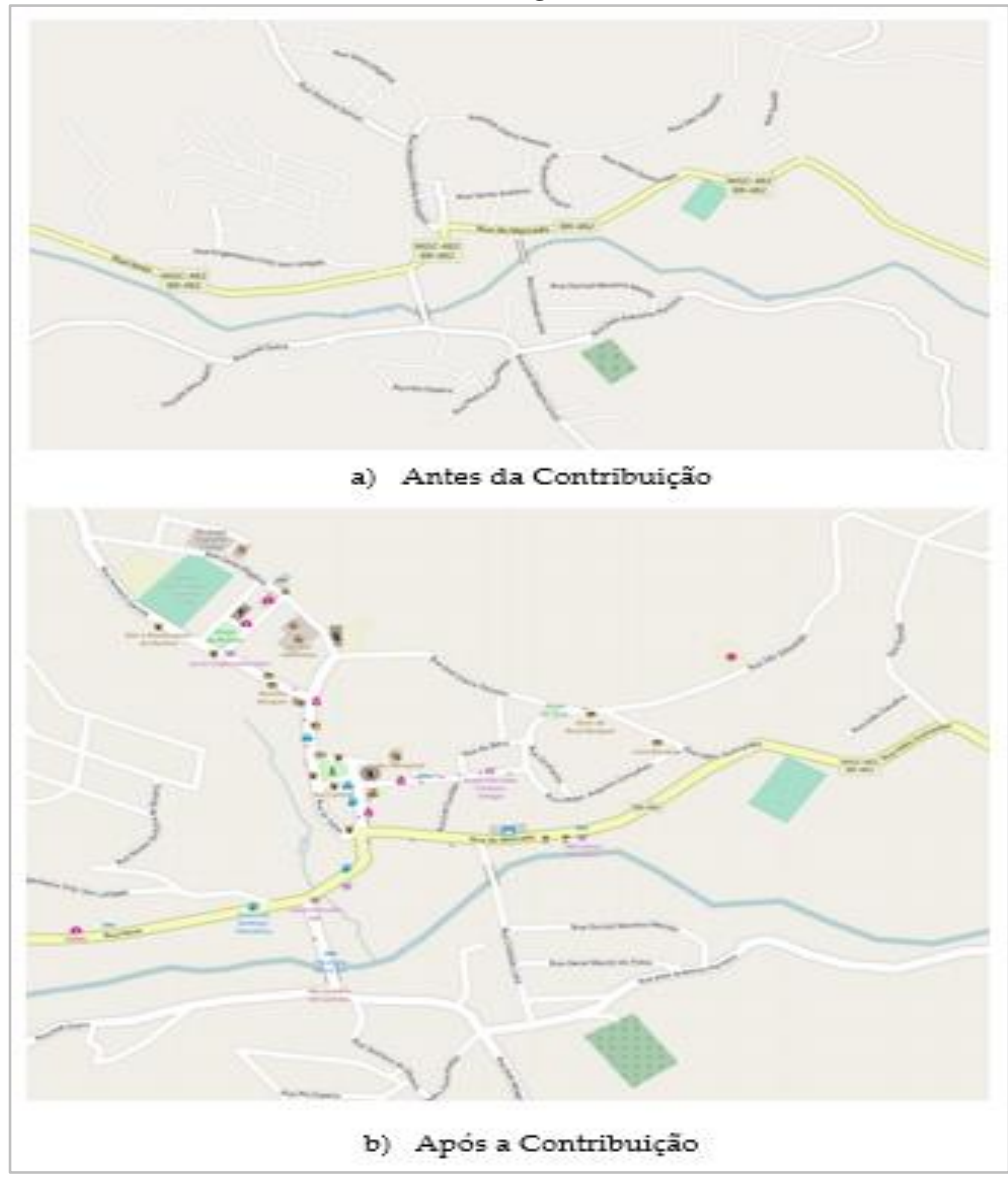

Fonte: elaborada pelos autores.

Rev. Bras. de Cartografia, vol. 70, Edição Especial "XXVII Congresso Brasileiro de 
A terceira etapa consistiu na modelagem conceitual do banco de dados. As Figuras 5 e 6 ilustram o resultado da modelagem conceitual realizada para o município de Florestal. Afim de auxiliar no entendimento do esquema produzido, cada classe/entidade modelada se encontra dentro de um tema (modelado como pacote UML) de acordo com seu grau de afinidade, desta forma é possível ter uma visão mais abrangente da modelagem e adquirir de imediato um conhecimento prévio do esquema conceitual. Neste trabalho foram modelados 5 temas, são eles: Esporte e lazer; Hidrografia; Vegetação; Edificação; e Malha Viária.

A Figura 5 ilustra a modelagem do Tema Edificação que contém a entidade genérica Edifícios. A entidade Edifícios é especializada por duas vezes; a primeira especialização separa as edificações em Público ou Privado; a segunda especialização informa quais objetos Públicos e Privados foram mapeados no mundo real e transformados em entidades.

A segunda parte da modelagem está ilustrada na Figura 6, a qual contém os demais Temas com suas respectivas entidades. Os Temas Malha Viária e Edificações possuem um relacionamento entre as entidades genéricas Rodovia e Edifícios. Os possíveis relacionamentos que possam existir entre entidades não foram modelados porque a base de dados importada do OSM vem sem relacionamentos. Posteriormente alguns relacionamentos semânticos podem ser estabelecidos e inseridos no banco de dados. Desta forma, apenas relacionamentos espaciais (ex.: proximidade, pertinência, cruza) são possíveis de serem aplicados em consultas.

É importante destacar que a modelagem de cada município irá conter entidades diferentes, devido as suas particularidades. Por exemplo, existem municípios com estádios e outros não. Portanto, é necessário utilizar os 5 Temas demonstrados anteriormente como base ao se iniciar a modelagem de um município. 
Figura 5 - Diagrama UML-GeoFrame do tema Edificação do município de Florestal

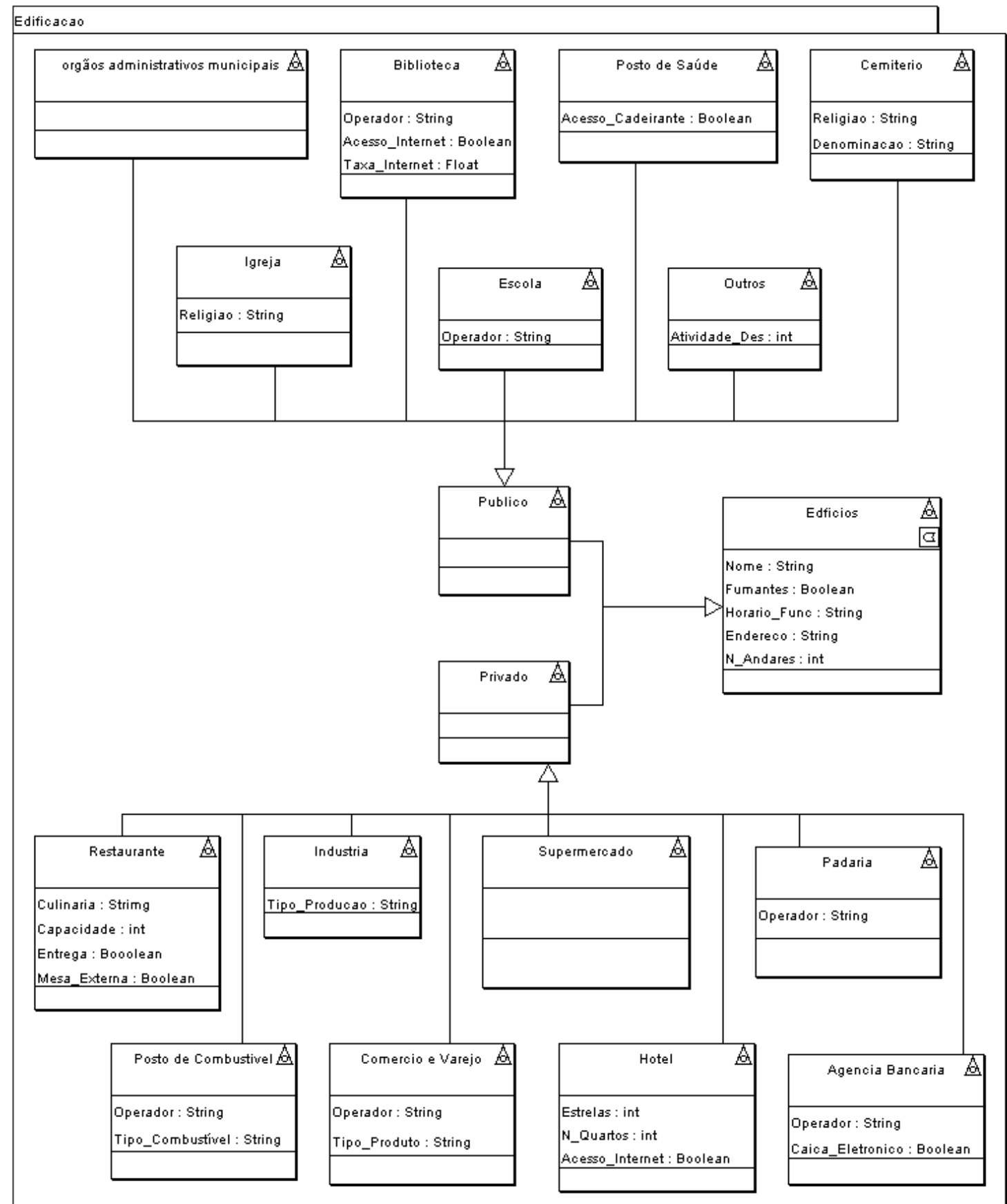

Fonte: elaborada pelos autores.

Os dados inseridos no OSM não apresentam um georreferenciamento acurado, mas estes contêm uma alta acurácia temática e temporal, já que o cadastro das feições, em geral, é feito por conhecedores da região, garantindo a acurácia temática. As alterações constantes dos usuários garantem uma fidelidade temporal, sendo esta uma das principais intenções dos sistemas de

Rev. Bras. de Cartografia, vol. 70, Edição Especial "XXVII Congresso Brasileiro de 
VGI. Entretanto, mesmo assim os dados cadastrados podem conter erros ou inconsistências e, na intenção de minimizar tais problemas, os mesmos passam por análises e validação que são realizadas por moderadores da comunidade OSM.

Figura 6 - Diagrama UML-GeoFrame dos temas Esporte e Lazer, Hidrografia, Vegetação e Malha Viária do município de Florestal
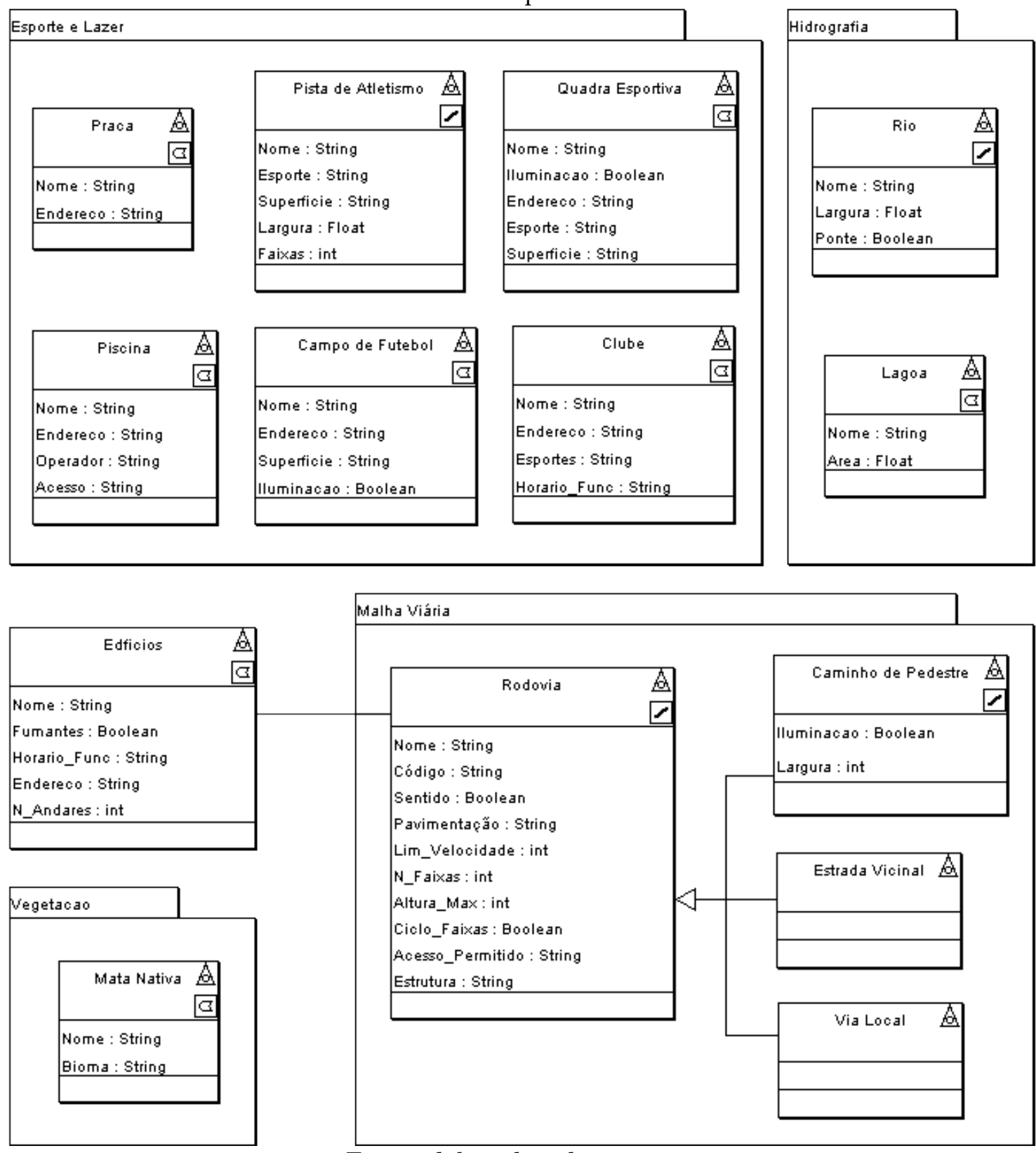

Fonte: elaborada pelos autores.

Rev. Bras. de Cartografia, vol. 70, Edição Especial "XXVII Congresso Brasileiro de 
$\mathrm{Na}$ avaliação e validação das relações topológicas, a utilização do software QGIS foi fundamental, pois o mesmo possui extensões para a manipulação de dados do OSM, o que facilita a implementação das relações espaciais e ao realizar consulta aos dados, os mesmos estão correlacionados. A validação dos dados não foi necessária, pois as feições foram cadastradas por moradores dos municípios estudados, garantindo a fidelidade temática e temporal.

Para a importação das feições para o banco de dados, utilizou-se coordenadas cartesianas planas no sistema de referência SIRGAS 2000, projetadas em UTM Zona $23 \mathrm{~S}$, com o objetivo de facilitar, por exemplo, a execução de operações de funções de distância e buffer.

Foram realizadas operações básicas de consultas ao banco de dados, como cálculo do comprimento de ruas, interseções de buffers e análise de melhores rotas. A seguir são descritos exemplos de consultas que podem auxiliar no processo de tomada de decisão pelos gestores municipais. Os códigos SQL de algumas consultas estão disponíveis no Quadro 1.

No munícipio de Paula Cândido foi realizada uma consulta sobre quais ruas que se encontravam a uma distância inferior a 100 metros do Posto de Saúde, através da ferramenta de intercessão; analisados quais os municípios vizinhos que circundam a cidade; calculado a quilometragem total de vias do município; e estudado qual o ponto de ônibus mais próximo a escola de ensino básico. A Figura 7 apresenta a análise hipotética de melhor região para construção de uma garagem entre a prefeitura e o posto de gasolina do município de Paula Cândido, utilizando a interseção de buffer com 300 metros cada. Sendo que o uso da interseção de buffer caracteriza-se como um recurso útil para realizar a análise de proximidade. A sintaxe dessa consulta se encontra no Quadro 1 - Consulta A. 
Figura 7 - Definição da melhor região para construção de uma garagem entre a prefeitura e o posto de gasolina do município de Paula Cândido.

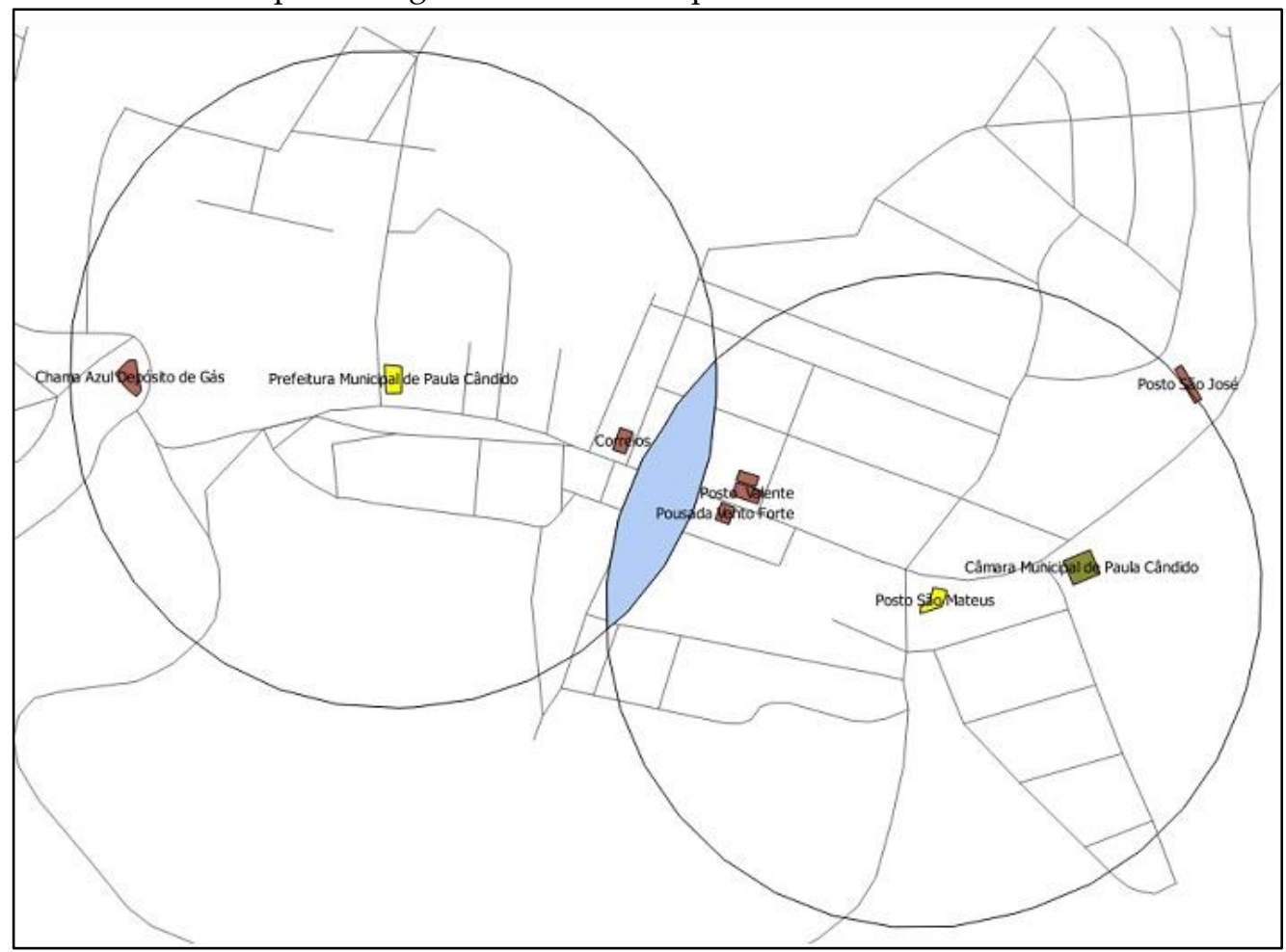

Fonte: elaborada pelos autores.

Quadro 1 - Exemplos de códigos SQL com funções espaciais.

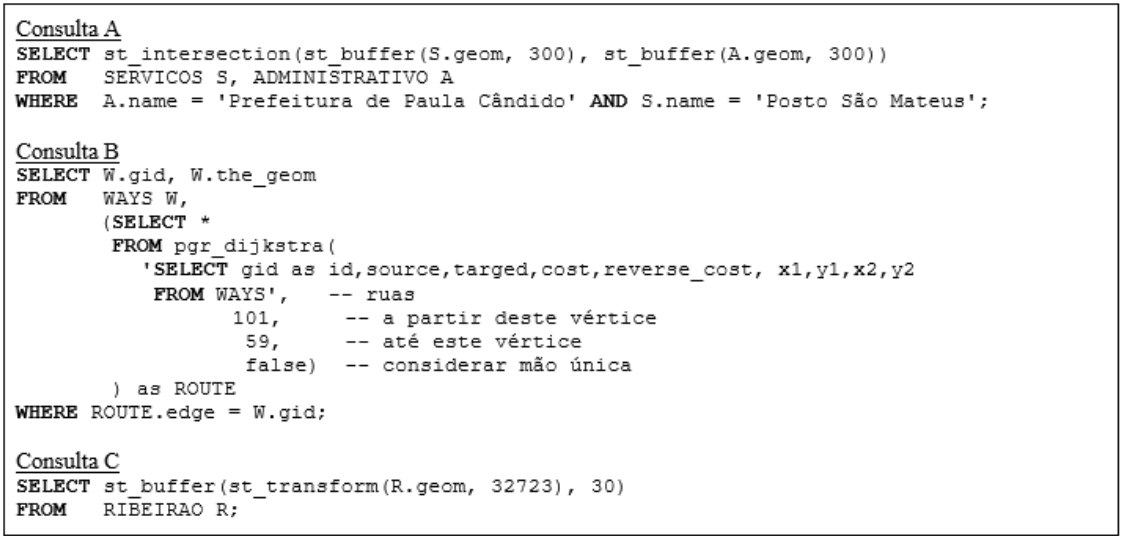

Fonte: elaborada pelos autores.

No município de Piranga foi consultado qual a drogaria mais próxima ao hospital e quais as ruas se encontravam em área de preservação da mata ciliar, sendo que para tal análise empregou-se a ferramenta de buffer em torno do Rio Piranga e posteriormente aplicou-se intercessão entre as vias e a área gerada pelo buffer. Analisou-se também qual é a região comercial do

Rev. Bras. de Cartografia, vol. 70, Edição Especial "XXVII Congresso Brasileiro de 
município, para isso gerou-se um buffer de 50 metros em torno de cada estabelecimento comercial, e visualmente pode-se perceber as regiões com maior existência de comércios, como mostra a Figura 8.

Figura 8 - Análise da região comercial do município de Piranga

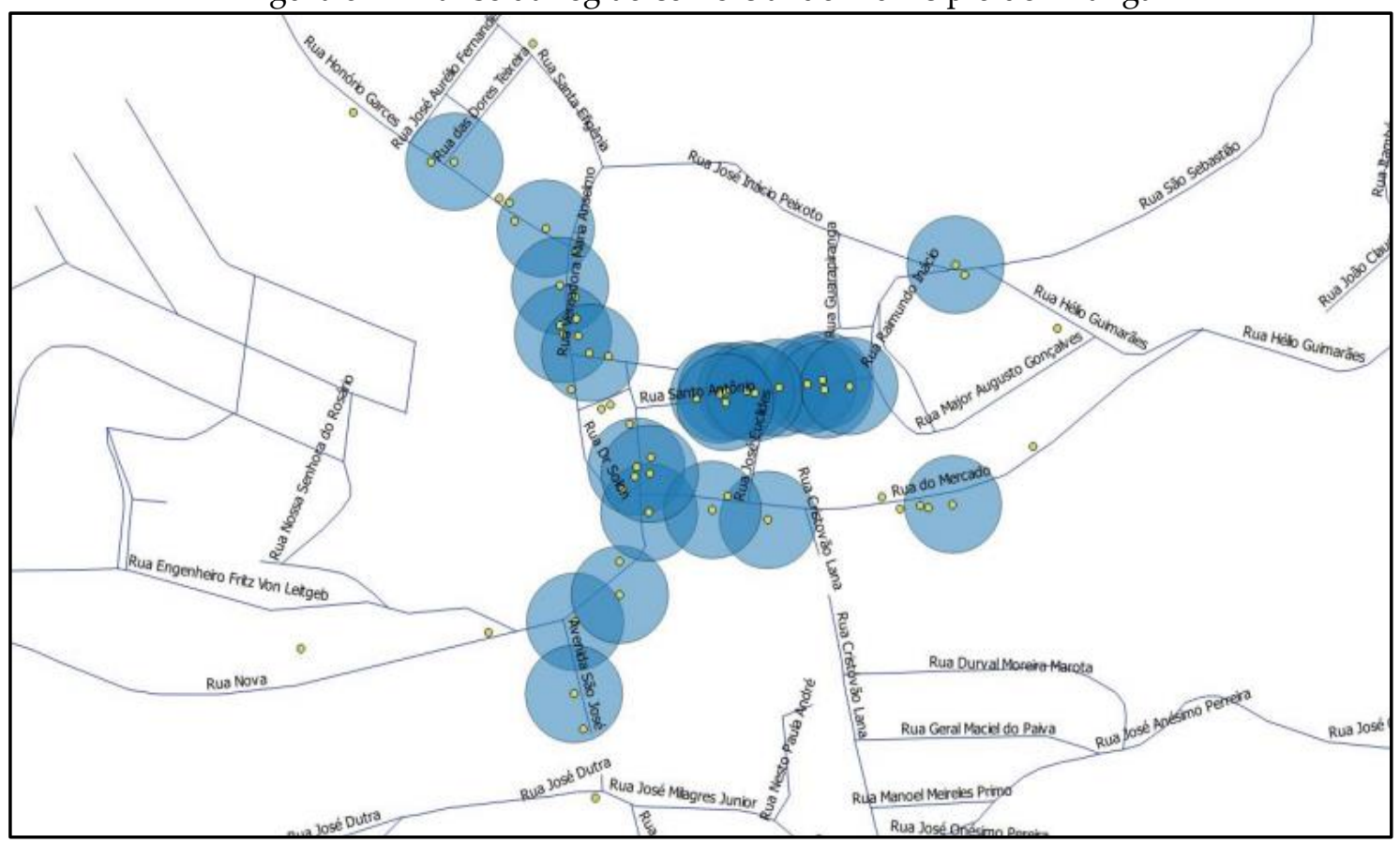

Fonte: elaborada pelos autores.

Uma operação importante disponibilizada no OSM é a determinação de rotas. Na quarta etapa deste trabalho verificou-se a possibilidade de utilizar os dados de arruamento do OSM na determinação de melhores rotas entre pontos de interesse.

O GeoPortal do OSM conta com uma funcionalidade de determinação de rotas. Conforme ilustrado na Figura 9, esta funcionalidade possibilita determinar rotas para pedestres, automóveis e bicicletas. Neste trabalho verificou-se a melhor rota entre a Unidade Básica de Saúde (UBS) e o Hospital da cidade de Manhumirim para o uso de um pedestre. O resultado da rota indicada pela funcionalidade do OSM está ilustrado na Figura 10.

Conforme descrito na seção anterior, a ferramenta osm2pgrouting da extensão pgRouting simplifica a importação das feições do OSM para um BDG (Obe e Hsu, 2017). Esta extensão possui diversos algoritmos para se 
determinar rotas a partir de funções de custo. Com a funcionalidade pgr_dijkstra, que utiliza o algoritmo de Dijkstra, é possível determinar rotas ótimas entre os nós da malha viária levando em consideração, ou não, o sentido das vias. O código SQL está disponível no Quadro 1 - Consulta B.

Figura 9 - Cálculo da melhor rota da UBS até o hospital, município de Manhumirim, pelo OSM.

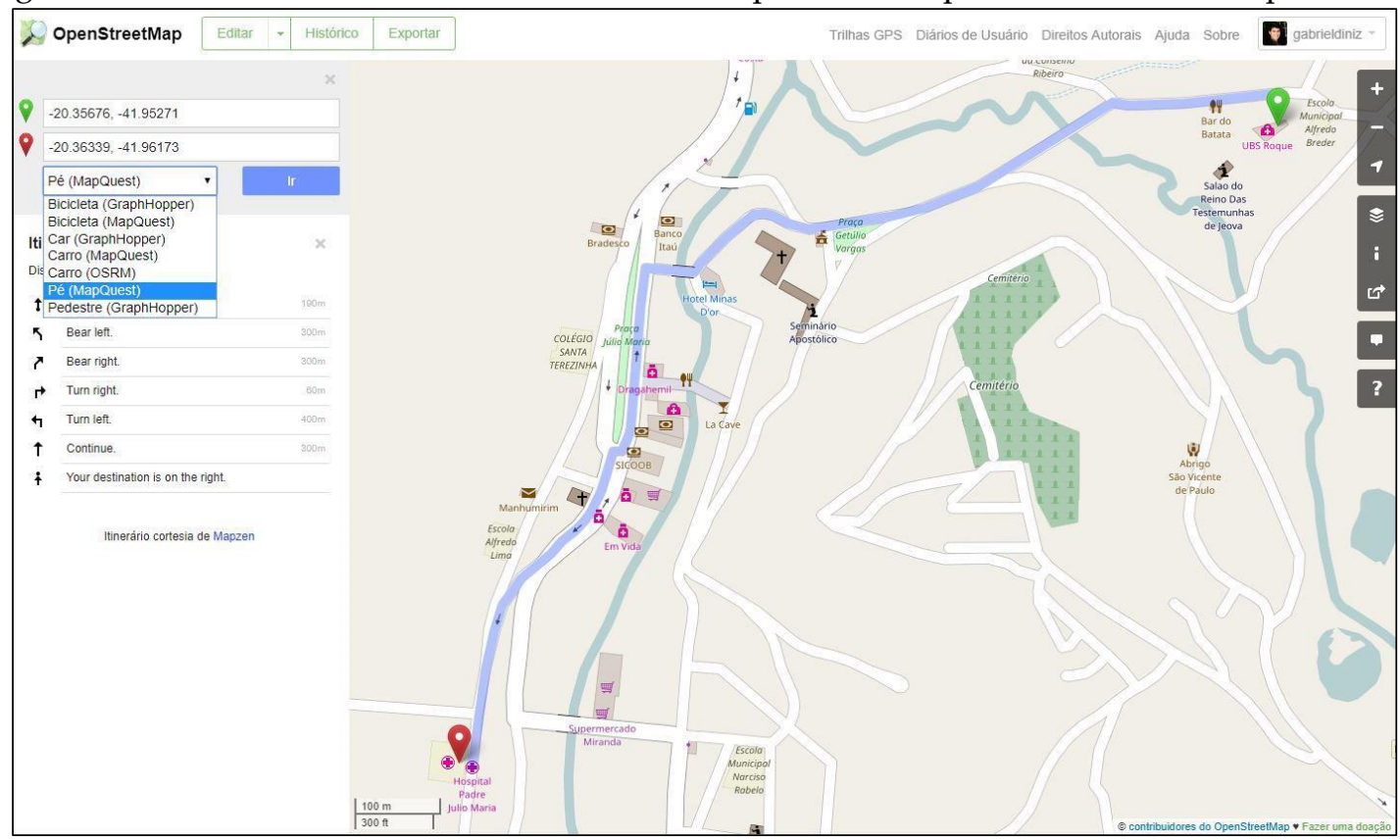

Fonte: elaborada pelos autores.

Figura 10 - Cálculo da melhor rota da UBS até o hospital, município de Manhumirim, pelo pgRouting.

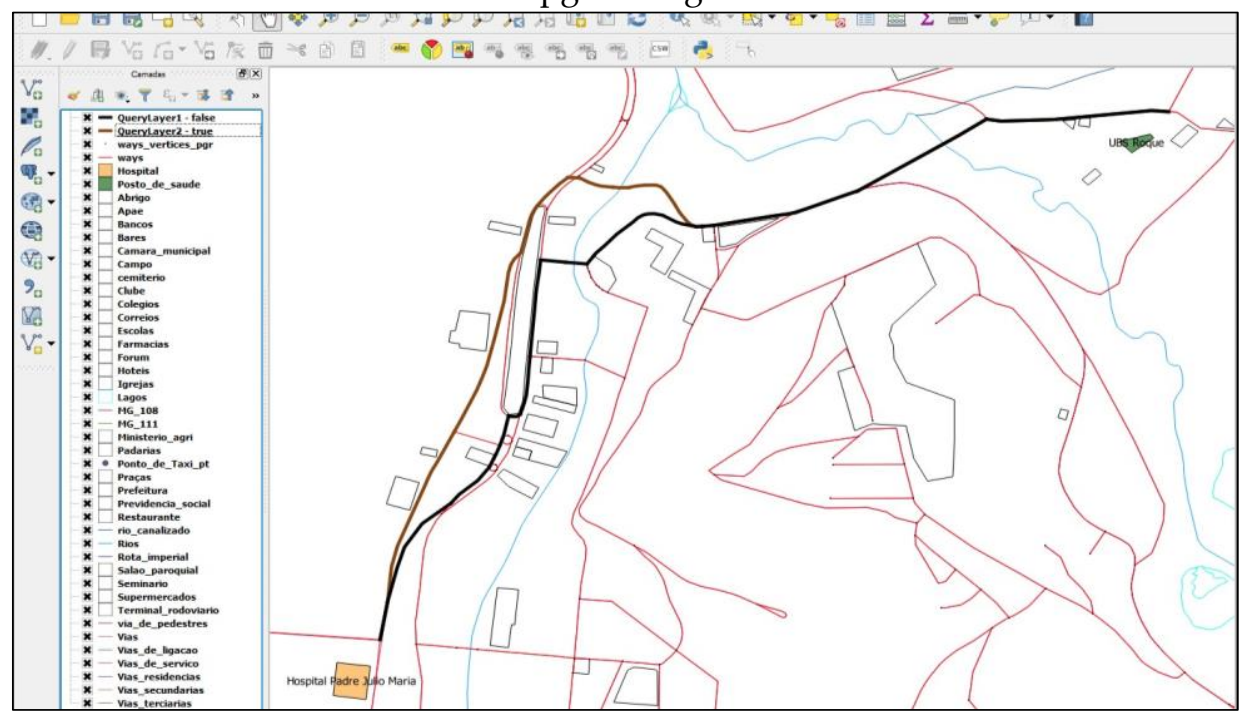

Fonte: elaborada pelos autores.

Rev. Bras. de Cartografia, vol. 70, Edição Especial "XXVII Congresso Brasileiro de 
A Figura 10 ilustra o resultado da melhor rota entre a UBS e o Hospital da cidade de Manhumirim calculados no pgRouting e visualizados no QGIS. A rota destacada na cor preta não leva em consideração o sentido das vias e a rota destacada na cor marrom considera este atributo.

Os resultados das rotas calculadas foram comparados e verificou-se que a melhor rota entre a UBS e o Hospital da cidade de Manhumirim calculada no pgRouting sem utilizar o sentido das vias é similar a rota calculada com a funcionalidade disponibilizada no GeoPortal do OSM para pedestres.

Por fim, a Figura 11 ilustra a região da Área de Preservação Permanente (APP) tomando como base um rio de largura máxima de 10 metros do município de Florestal, onde os administradores podem visualizar a área que deveria ser coberta por vegetação e não dispor de construções civis e podem avaliar as construções em área de APP e devem ser fiscalizadas. Tal representação foi gerada utilizando a operação Buffer, resultando em uma área sombreada de 30m a partir do Rio, tomado como referência.

Figura 11 - APP no município de Florestal.

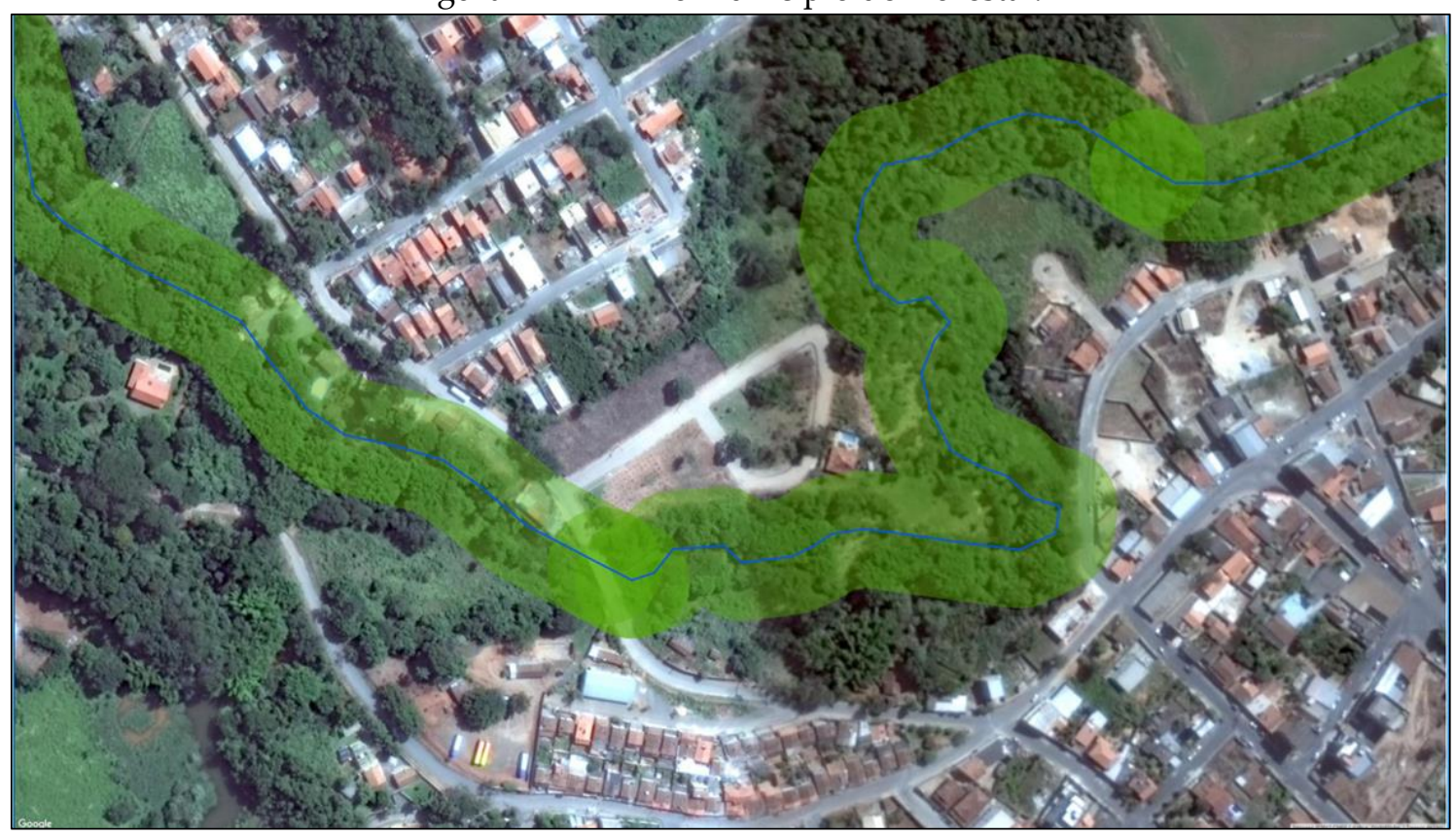

Fonte: elaborada pelos autores. 
Neste município também foi avaliada a distância entre as escolas e o posto de saúde; calculada a distância entre a capital mineira Belo Horizonte e o campus da Universidade Federal de Viçosa, localizado no município; consultada qual a lagoa de maior área; e calculada a área total de espelho d'água existente na região urbana, considerando as lagoas e piscinas cadastradas. O código SQL desta consulta está no Quadro 1 - Consulta C.

\section{Conclusões}

Neste trabalho considerou-se o uso de VGI como fonte de dados para cartografia básica de municípios de pequeno porte. Foram usadas ferramentas de software livre e sem nenhum custo financeiro foram elaboradas bases cartográficas com alta acurácia temática e temporal.

Os resultados experimentais permitiram concluir que o trabalho proposto apresenta estratégias que podem auxiliar os gestores municipais no planejamento e tomada de decisões que afetam diretamente a vida dos cidadãos e os recursos financeiros destinados ao município. Assim, é possível elucidar e desenvolver projetos a fim de prover melhorias na infraestrutura urbana, cadastro de áreas construídas, redes de transmissão de energia, abastecimento de água e esgoto, serviços públicos, pontos turísticos, áreas de preservação, entre outros.

A abordagem desenvolvida e implementada pelo presente trabalho é um bom primeiro passo para o aprimoramento de pesquisas que usam VGI, além de mostrar aspectos positivos ao combinar sistemas de software livre com as tarefas desenvolvidas na administração municipal.

Como trabalhos futuros pode-se considerar aplicar os métodos aqui propostos em estudos na área de Smart Cities. Isso permite uma melhor utilização dos recursos públicos, aumento da qualidade dos serviços oferecidos aos cidadãos e redução dos custos operacionais da administração pública. 


\section{Agradecimentos}

Os autores agradecem à Coordenação de Aperfeiçoamento de Pessoal de Nível Superior (CAPES) e Fundação de Amparo à Pesquisa do Estado de Minas Gerais (FAPEMIG) pelo apoio financeiro.

\section{Referências}

ARSANJANI, J. J.; ZIPF, A.; MOONEY, P.; HELBICH M., 2015. OpenStreetMap in GIScience. Experience, Research and Applications. Springer International Publishing.

BUDHATHOKI, N. R., 2007. Reconceptualization of user is essential to expand the voluntary creation and supply of spatial information, In Proceedings of Workshop on Volunteered Geographic Information. Santa Barbara, California, USA.

CÂMARA, J. H. S.; VEGI, L. F. M.; PEREIRA, R. O.; GEÖCZE, Z. A.; Lisboa-Filho, J.; SOUZA, W. D. de., 2017. ClickOnMap: A platform for development of volunteered geographic information systems, In Proceedings of 12th Iberian Conference on Information Systems and Technologies (CISTI), Lisbon, pp. 1-6.

ELMASRI, R. E.; NAVATHE, S., 2005. Sistemas de Banco de Dados - Fundamentos e Aplicações. $4^{\circ}$ edição, AddisonWesley, São Paulo.

GOODCHILD, M.F., 2007. Citizens as sensors: the world of volunteered geography. GeoJournal, Vol. 69, pp. 211-221.

HAKLAY, M., e WEBER, P., 2008. OpenStreetMap: Mapas de rua gerados pelo usuário. IEEE Pervasive Computing, pp. 12 - 18.

HEIDER, K.; LOPEZ, J. M. R; SCHEFFRAN, J. 2018. The potential of volunteered geograhic information to investigate peri-urbanization in the conservation zone of Mexico City. Env, monitoring and assessment, v. 190, n. 4, pp.190-219.

HIRATA, E.; GIANNOTTI, M.A.; LAROCCA, A. P. C.; QUINTANILHA, J. A., 2015. Flooding and inundation collaborative mapping-use of the Crowdmap/Ushahidi platform in the city of Sao Paulo, Brazil. Journal of Flood Risk Management, v. 11, p. S98-S109.

HORITA, F. E.; DE ALBUQUERQUE, J. P.; DEGROSSI, L. C.; MENDIONDO, E. M., 2015. Development of a spatial decision support system for flood risk 
management in Brazil that combines volunteered geographic information with wireless sensor networks. Computers e Geosciences, v. 80, pp. 84-94.

IBGE (Instituto Brasileiro de Geografia e Estatística), 2017. Brasil em Síntese. Disponível em: <https://cidades.ibge.gov.br/>. Acesso: 16 de abril de 2018.

IDOETA, I. V., 2005. Concepção de Bases Cartográficas para Projetos de Engenharia. (Magister Scientiae) - Escola Politécnica, Universidade de São Paulo, São Paulo - SP.

KUSUMO, A. N. L.; RECKIEN, D.; VERPLANKE, J., 2017. Utilising volunteered geographic information to assess resident's flood evacuation shelters. Case study: Jakarta, Applied Geography, v. 88, pp. 174-185.

LISBOA-FILHO, J; IOCHPE, C., 2008. Modeling with a UML profile. In: Shashi Shekhar and Hui Xiong. Encyclopedia of GIS. New York: Springer. p.691-700 LISBOA-FILHO, J.; SODRÉ, V. F.; DALTIO, J.; RODRIGUES JUNIOR, M. F.; VILELA, V., 2004. A CASE tool for geographic database design supporting analysis patterns, in Proceedings of Workshop on Conceptual Modeling for GIS (CoMoGIS), Shanghai, China. Springer LNCS 3289.

MARTINS, M.O.; RIBAS, R. P.; RENZO, R. F.; LONGO, E.S.; OLIVEIRA, F. H., 2017. Plataforma para coleta de informação geográfica voluntária acerca da situação de estruturas relacionadas à microdrenagem urbana, em Anais do XXVII Congresso Brasileiro de Cartografia, Rio de Janeiro.

MOREIRA, R. B; DEGROSSI, L. C.; DE ALBUQUERQUE, J. P., 2015. An experimental evaluation of a crowdsourcing-based approach for flood risk management, In Proceedings of 12th Workshop on Experimental Software Engineering (ESELAW), Lima, Peru, pp. 1-11.

OBE, R. O.; HSU, L. S., 2017. pgRouting: A practical guide. Locate Press.

OPEN DATA COMMONS, 2017. Open Data Commons Open Database License

(ODbL). Site: https://opendatacommons.org/licenses/odbl/. Acessado em julho de 2017.

OSM Wiki, 2018, OpenStreetMap Wiki, Site: $<$ https://wiki.openstreetmap.org/wiki/Pt:Bing_Maps>, Acessado em abril de 2018.

SZTUTMAN, P., 2014, Análise da qualidade posicional das bases do Google Maps, Bing Maps e da Esri para referência espacial em projetos em SIG: aplicação para 
o município de São Paulo. 182p. (Magister Scientiae) - Escola Politécnica da USP, Departamento de Engenharia de Transportes, São Paulo - SP.

WAN, Z.; HONG, Y.; KHAN, S.; GOURLEY, J; FLAMIG; Z.; KIRSCHBAUM, D.; TANG, G., 2014. A cloud-based global flood disaster community cyberinfrastructure: Development and demonstration. Environmental Modelling e Software, v.58, pp. 86-94.

ZANETTI, J.; PAULA, R. M.; SANTOS, A. P.; MEDEIROS, N. G., 2016. Avaliação da acurácia posicional planimétrica de ortoimagens disponibilizadas nos sistemas de informações geográficas. Revista Brasileira de Cartografia, Vol. 68, N 7, pp. 1341-1352. 